\title{
Association between $A K T$ rs2494752 single nucleotide polymorphism and the risk of metastasis in hepatocellular carcinoma
}

\author{
ZHAOHUI WANG ${ }^{*}$, HUILING FU* ${ }^{*}$ and WEI LI* \\ Department of Hepatology, Qingdao Sixth People's Hospital, \\ Qingdao, Shandong 266033, P.R. China
}

Received December 7, 2017; Accepted April 26, 2018

DOI: $10.3892 / \mathrm{ol} .2018 .9060$

\begin{abstract}
Hepatocellular carcinoma (HCC) is one of the most common types of human tumors, which is characterized by high morbidity and mortality rates. AKT1 transcriptional activity is implicated in HCC initiation and development. In the present study, the effects of rs2494752 single nucleotide polymorphism (SNP) on AKT1 transcriptional activity in the progression of HCC cells were investigated. A case-control study was analyzed in 1,056 HCC patients and 1,080 healthy individuals using the PCR assay method. Results indicated AKT1 expression levels were up-regulated in HCC tissue compared to adjacent normal tissues. Furthermore, a higher frequency of $A K T$ rs2494752 AG and AA genotypes were observed in HCC cases $(\mathrm{P}=0.0046)$. Gene polymorphism identified $\mathrm{C}$ and $\mathrm{T}$ alleles were frequency in $\mathrm{HCC}$ patients compared to healthy individuals. Individuals harboring $A K T$ rs2494752 AG/AA genotype had a vital increased susceptibility to HCC in the dominant model $(\mathrm{P}=0.0028)$. In addition, $A K T 1$ rs2494752 GG genotype showed an increasing of $A K T 1$ promoter activity determined by the luciferase assay. Furthermore, it was demonstrated that AKT1 rs2494752 $\mathrm{GG}$ and $\mathrm{C}$ polymorphism was more aggressive than other AKT1 rs2494752 cancer cells. Moreover, AKT1 rs2494752 GG markedly increased rates of response to NCT chemotherapy. Additionally, results revealed that $A K T 1$ rs2494752 GG and $\mathrm{C}$ increased the risk factors of HCC. In conclusion, these results indicate that $A K T 1$ rs 2494752 polymorphisms may be regarded as a candidate gene in assessing the
\end{abstract}

Correspondence to: Professor Wei Li, Department of Hepatology, Qingdao Sixth People's Hospital, 9 Fushun Road, Shibei, Qingdao, Shandong 266033, P.R. China

E-mail: liweiqingdaoprof@163.com

*Contributed equally

Key words: HCC, AKT1, rs2494752, SNP, metastasis susceptibility, metastasis and responses to chemotherapy in the progression of hepatocellular carcinoma.

\section{Introduction}

Hepatocellular carcinoma (HCC) is aggressive hypervascular solid tumor, and the vascularity is significantly different from peripheral parenchyma of liver (1). Advanced stage HCC possesses aggressive potent for adjacent and distant cells and/or organs (2,3). Many systematic review and meta-analysis have indicated that hepatocellular carcinomas presents a high recurrence and the second cancer-death rates even received surgery, radiotherapy, chemotherapy and biotherapy $(4,5)$. Previous reports have indicated that the current therapeutic schemes remain limited, especially for patients with advanced hepatocellular carcinoma, which exhibited poor survival in a 5-year survival statistical survey $(6,7)$. Therefore, it is an urgent need to explore novel therapeutic targets for hepatocellular carcinoma.

Clinical therapies are eagerly needed for inhibiting migration and invasion to maximal prolong survival of patients with hepatocellular carcinoma $(8,9)$. In recent year, various gene polymorphisms have been reported to association with HCC metastasis, which become a potential strategy for determining HCC diagnosis, susceptibility, target, metastasis, apoptotic sensibility and prognosis (10-13). Report has indicated that $A K T$ gene polymorphisms may be associated with prostate cancer, gastric cancer and osteosarcoma (14-16). Yin et al (17), reported that PI3K/Akt pathway involved in in human HCC cell lines by regulation of metastasis-related gene expression. Additionally, down-regulation of PI3K/Akt-PAK1 signal pathway could inhibit the metastasis properties of hepatocellular carcinoma, which suggested that AKT is a potential target for the treatment of hepatocellular carcinoma (18).

In the present study, we investigated the effects of rs 2494752 polymorphism on $A K T 1$ gene transcriptional activity in 1,056 HCC patients and 1,080 healthy individuals using the TaqMan assay method. Here, we reported that AKT1 rs2494752 GG and $\mathrm{C}$ polymorphism HCC presented more aggressive. We analyzed the association between AKT1 rs2494752 gene polymorphism and responses to chemotherapy in the progression of hepatocellular carcinoma. 


\section{Materials and methods}

Study design, subjects and sampling. 1056 HCC patients and 1,080 healthy individuals were included in this retrospective cohort in Chinese Han population collected form archives department of Qingdao Sixth People's Hospital from May 2008 to July 2015. The numbers of male and female HCC patients and healthy individuals were approximate equal. Patients with cancer history were excluded. This study was approved by the ethics committee of Qingdao Sixth People's Hospital (ethics code: QDPHCAN132X1P). All patients were asked to provide $5 \mathrm{ml}$ venous blood and were required to write informed consent with signature.

Reverse transcription-quantitative polymerase chain reaction $(R T-q P C R)$. Total RNA was extracted from HCC tissues and adjacent normal tissues using an RNeasy Mini kit (Qiagen, Inc., Valencia, CA, USA), according to the manufacturers' protocol. RNA was reversed transcribed using a PrimeScript RT Master Mix kit (Takara Bio, Inc., Otsu, Japan). All forward and reverse primers were synthesized by Invitrogen (Thermo Fisher Scientific, Inc., Waltham, MA, USA). The sequences were as follow: AKT1, Forward: 5'-CTTCCTCACAGCCCTGAA GTAC-3', Reverse: 5'-GCATGAGGTTCTCCAGCTTGAG-3'; GAPDH, Forward: 5'-CCAGGGCTGCTTTTAACTCTG-3', Reverse: 5'-CGCTCCTGGAAGATGGTGATG-3'. For amplification diluted cDNA was combined with a reaction mixture containing SYBR-Green PCR core reagents (cat. no. 4304886; Applied Biosystems; Thermo Fisher Scientific, Inc.). Relative mRNA expression levels were calculated using the $2^{-\Delta \Delta C q}$ method (19). PCR cycling was performed under the following conditions: $94^{\circ} \mathrm{C}$ for $30 \mathrm{sec}$ and 45 cycles of $95^{\circ} \mathrm{C}$ for $5 \mathrm{sec}, 56^{\circ} \mathrm{C}$ for $10 \mathrm{sec}$ and $72^{\circ} \mathrm{C}$ for $10 \mathrm{sec}$. The results were expressed as the $\mathrm{n}$-fold of the control.

Migration assay. The migration of HCC cells were evaluated using transwell plates. The isolated HCC cells were directly seeded on the upper chamber $(8 \mathrm{~mm}$ pore size, $6.5 \mathrm{~mm}$ diameter; Corning Incorporated, Corning, NY, USA) with DMEM (Thermo Fisher Scientific, Inc.). The lower chamber was filled with DMEM (Thermo Fisher Scientific, Inc.) supplemented with 10\% FBS (Thermo Fisher Scientific, Inc.). Cells were then incubated at $37^{\circ} \mathrm{C}$ for $48 \mathrm{~h}$. The migrated cells from at least six random microscopic fields (x200) were counted under a light microscope (Olympus Corporation, Tokyo, Japan).

Western blot analysis. HCC tissues and adjacent normal tissues were homogenized in a lysate buffer containing protease-inhibitor (P3480; Merck KGaA, Darmstadt, Germany) and were centrifuged at $6,000 \mathrm{xg}$ at room tempreture for $10 \mathrm{~min}$. Western blot analysis was subsequently performed as previously described (20). Protein concentration was measured by a BCA protein assay kit (Thermo Fisher Scientific, Inc.). Protein samples $(10 \mu \mathrm{g} / \mathrm{lane})$ were resolved by $12.5 \%$ SDS-PAGE and then transferred to polyvinylidene fluoride membranes (Merck KGaA). After blocking with $2 \%$ bovine serum albumin (Sigma-Aldrich; Merck KGaA), rabbit anti-human AKT1 (ab81283) or GAPDH (ab9485) antibodies (all, 1:2,000; Abcam, Shanghai, China) were incubated with protein samples for $2 \mathrm{~h}$ at room temperature. Membranes were washed with
PBS for $15 \mathrm{~min}$ at room temperature and then incubation with horseradish peroxidase-conjugated polyclonal anti-rabbit immunoglobulin G antibodies (1:10,000; PV-6001; OriGene Technologies, Inc., Beijing, China) for $1 \mathrm{~h}$ at room temperature. Signals were visualized by chemiluminescence detection (Z370398; Merck KGaA). Densitometric quantification of the immunoblot data was performed using Quantity-One software (v3.24; Bio-Rad Laboratories, Inc., Hercules, CA, USA).

Immunohistochemistry. Immunohistochemical procedures were performed as described previously (21). HCC tissues and adjacent normal tissues were frozen and coronal sections were cut in a cryostat. The tissues were cut into $4-\mu \mathrm{m}$ thick sections and mounted on glass slides. The paraffinized sections were heated in an oven at $65^{\circ}$ for $24 \mathrm{~h}$, dewaxed to water and rinsed with PBS three times. The washed sections were placed in EDTA buffer (Beinuo Bioscience Inc., Shanghai, China), and then boiled at a low heat following an interval of $10 \mathrm{~min}$ at $65^{\circ} \mathrm{C}$ for a total of 3 intervals. Following natural cooling, the sections were washed with PBS three times, and were placed into 3\% hydrogen peroxide solution (Beina Bioscience Inc.), for incubation at room temperature for $10 \mathrm{~min}$, to block endogenous peroxidase. Free-floating sections were rinsed with PBS and placed in a solution containing primary mouse monoclonal antibodies directed against AKT1 (ab81283, 1:2,000; Abcam) at $4^{\circ} \mathrm{C}$ overnight. After rinsing with PBS, sections were incubated for $1 \mathrm{~h}$ at room temperature with horseradish peroxidase (HRP)-conjugated goat anti-rabbit IgG mAb (1:5,000 dilution; PV-6001, OriGene Technologies, Inc., Beijing, China). The sections were then washed with PBS and observed by fluorescent video microscopy (BZ-9000; Keyence Corporation, Osaka, Japan).

DNA genotyping. All candidates' loci of AKT1 gene for tag gene were based on NCBI dbSNP database and SNP info. The genomic DNA was $10 \mu \mathrm{g}$ of genomic DNA were isolated from extracted by the method of buffy-coat fractions with TIANamp blood DNA kit (Tiangen Biotech Co., Ltd., Beijing, China) (50 ng of genomic DNA, $200 \mu \mathrm{M}$ dNTP, 2.5 units of Taq DNA polymerase, and $200 \mu \mathrm{M}$ primers) and used for PCR amplification followed preliminary denaturation at $94^{\circ} \mathrm{C}$ for $2 \mathrm{~min}$, followed by 35 cycles of $94^{\circ} \mathrm{C}$ for $30 \mathrm{sec}$, annealing temperature reduced to $64^{\circ} \mathrm{C}$ for $30 \mathrm{sec}$, and $72^{\circ} \mathrm{C}$ for $10 \mathrm{~min}$ by volume of $20 \mu \mathrm{l}$ containing $50 \mathrm{ng}$ of genomic DNA, $200 \mu \mathrm{M}$ dNTP, 2.5 units of Taq DNA polymerase, and $200 \mu \mathrm{M}$ primers. PCR primers (Forward: 5'-CTTCCTCACAGCCCT GAAGTAC-3', Reverse: 5'-GCATGAGGTTCTCCAGCT TGAG-3') were designed using Sequenom Assay Design v3.1 software (Sequenom, San Diego, CA, USA). Genotyping of $A K T 1$ gene was conducted by PCR-restriction fragment length polymorphisms (RFLP) as described previously $(22,23)$.

Trans-well invasion assay. HCC tissues were obtained from Qingdao Sixth People's Hospital. Transwell invasion assays were carried out in 24-well plates. In brief, HCC cells in serum-free medium contained Matrigel insert filters at 1:6 dilutions. The lower chamber was filled with culture medium with $10 \%$ FBS+DMEM. After incubation for $48 \mathrm{~h}$ at $37^{\circ} \mathrm{C}$, cells were fixed and stained with $0.1 \%$ crystal violet (Sigma-Aldrich; Merck KGaA). The cells that invaded through the Matrigel membrane were quantified. 
Luciferase assays. HCC cells were cultured in a 24-well culture plates for $24 \mathrm{~h}$. Each well was transfected with $1.0 \mu \mathrm{g}$ of each AKT1-reporter plasmid (pRL-SV40) with the allele C or T using Lipofectamine 2000 (Invitrogen; Thermo Fisher Scientific, Inc.). The control-reporter vector was used as a negative control. HCC cells were transfected with $1.0 \mu \mathrm{g}$ pRL-SV40 (containing the Renilla luciferase gene) plasmids per well. HCC cells were then lysed with the passive lysis buffer (Promega Corporation, Madison, WI, USA) and for luciferase expression activity analysis using the Dual-Luciferase Reporter Assay System (Promega Corporation) after 48-hour transfection. Three independent transfection experiments were performed in this experiment.

Statistical analysis. Continuous variables were shown as mean \pm SD and analyzed by student t test. All data were analyzed using SPSS Statistics 19.0 and Graphpad Prism v5.0 with the help of Microsoft Excel. Allele and genotype frequencies were calculated by using direct counting. Hardy-Weinberg equilibrium (HWE) and the differences between allele and genotype frequencies were calculated using Fisher's exact test. Results of allele and genotype frequencies were determined by STATA SE 12.1 software. The risk of HCC was analyzed by regression analysis. ${ }^{*} \mathrm{P}<0.05$ was considered to indicate a statistically significant difference.

\section{Results}

Characteristics of study population. This study included 1056 HCC with pathologically confirmed and a group of 1080 ageand gender- matched healthy individuals. The age between HCC patients and healthy individuals $42.6 \pm 10.7$ and was $50.4 \pm 12.8$ (median: 50.4 years) and 50.4 14.6 (median: 50.4 years), respectively. There were no significant differences in the distributions of age between patients and healthy individuals $(\mathrm{P}=0.726)$. In this cohort, 348 (32.8\%) patients underwent preoperative NCT (CE(A)F regimen), and $636(60.2 \%)$ of the patients received postoperative anthracycline-based chemotherapy. The characteristics of patients were summarized in Table I.

Analysis of AKT1 expression in hepatocellular carcinoma. AKT1 gene and protein expression levels were higher in HCC tissues and adjacent normal tissues from the same patients. We showed that AKT1 gene levels were up-regulated in HCC tissues compared to adjacent normal tissues (Fig. 1A). Western blot demonstrated that AKT1 protein levels were higher in HCC tissues than adjacent normal tissues (Fig. 1B). Immunohistochemistry found that AKT1 expression was markedly increased in HCC tissues compared to adjacent normal tissues (Fig. 1C). These data suggest that AKT1 may be associated with the progression of hepatocellular carcinoma.

Meta-analysis AKT1 rs2494752 gene polymorphism between HCC patients and healthy individuals. We analyzed AKT1 rs2494752 gene polymorphism allele and genotype polymorphism in hepatocellular carcinomamigraine patients and healthy individuals. We showed that genotypes of AKT1 rs2494752 were AG, AA, C and T in HCC patients and healthy individuals. We demonstrated that a higher frequency of AKT rs2494752 AG and AA genotypes were observed
Table I. The characteristics of patients.

\begin{tabular}{lccc}
\hline Variables & Patients & Healthy & P-value \\
\hline No. & 1056 & 1080 & $>0.05$ \\
Man & 536 & 538 & $>0.05$ \\
Woman & 520 & 542 & $>0.05$ \\
Age & $50.4 \pm 12.8$ & $50.4 \pm 14.6$ & $>0.05$ \\
Treatment & & - & - \\
Preoperative NCT & 348 & - & - \\
Chemotherapy & 636 & & \\
\hline
\end{tabular}

in HCC cases $(\mathrm{P}=0.0046$ and $\mathrm{P}=0.0040$; Fig. 2A and $\mathrm{B})$. TaqMan assay method revealed that $\mathrm{C}$ and $\mathrm{T}$ alleles in $A K T 1$ rs2494752 gene polymorphism were frequency in HCC patients compared to healthy individuals $(\mathrm{P}=0.0078$ and $\mathrm{P}=0.0063$; Fig. 2C and D). These results suggest that $A K T 1$ rs2494752 gene polymorphism is higher frequencies in HCC patients compared to healthy individuals.

Effects of the rs2494752 polymorphism on AKT1 transcriptional activity and progression of hepatocellular carcinoma. The effects of the rs2494752 polymorphism on AKT1 transcriptional activity and progression of HCC were analyzed in human tissues. The luciferase assay showed that patients harboring AKT1 rs2494752 GG genotype promoted AKT1 promoter activity ( $\mathrm{P}=0.068$; Fig. 3A). Aggressiveness assay revealed that $A K T 1 \mathrm{rs} 2494752 \mathrm{GG}$ and C polymorphism HCC cells presented more aggressive than other AKT1 rs2494752 cancer cells $(\mathrm{P}=0.026$ and $\mathrm{P}=0.032$; Fig. $3 \mathrm{~B}$ and $\mathrm{C})$. These results suggest that the $A K T 1$ rs2494752 polymorphism promotes AKT1 transcriptional activity and aggressiveness of hepatocellular carcinoma.

Association of AKT1 rs2494752 gene polymorphism on response to NCT and the survival of HCC patients. Of the HCC patients, 348 (32.8\%) patients underwent preoperative NCT (CE(A)F regimen), and 636 (60.2\%) of the patients received postoperative anthracycline-based chemotherapy. The the percentages of AKT1 rs2494752 AA and AG genotypes were 38.6 and $61.4 \%$, respectively. The percentages of AKT1 rs2494752 $\mathrm{C}$ and $\mathrm{T}$ alleles were 45.2 and $54.8 \%$ respectively. AKT1 rs2494752 GG significantly increased rates of response to NCT chemotherapy compared to the AA genotype (adjusted $\mathrm{OR}=0.325,95 \% \mathrm{CI}=0.107-0.992$, $\mathrm{P}=0.048$; Fig. 4A). We showed that there were no significant differences between AKT1 rs2494752 C and T alleles in responding to NCT chemotherapy (Fig. 4B). As shown in Fig. 4C and D, we found AKT1 rs2494752 GG patients had a long-term survival, while no significant differences between AKT1 rs2494752 C and T alleles for HCC patients. These results suggest $A K T 1$ rs2494752 gene polymorphism is response to NCT and the survival of HCC patients.

Meta-analysis between AKT1 rs2494752 gene polymorphism and risk of hepatocellular carcinoma. To further evaluate the association between AKT1 rs2494752 gene polymorphism and risk of hepatocellular carcinoma, multiple 
A

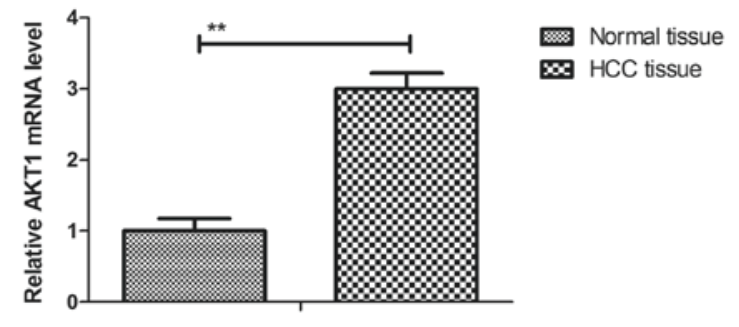

B

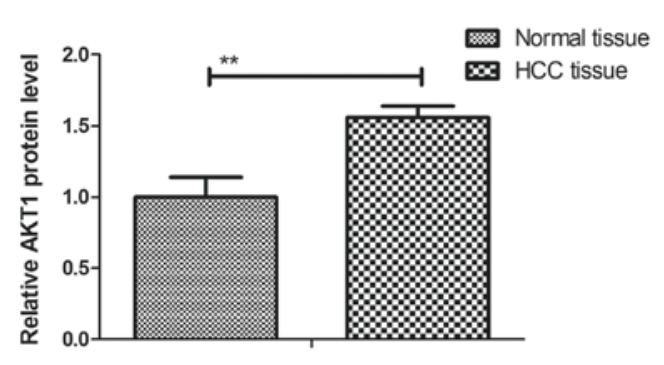

C
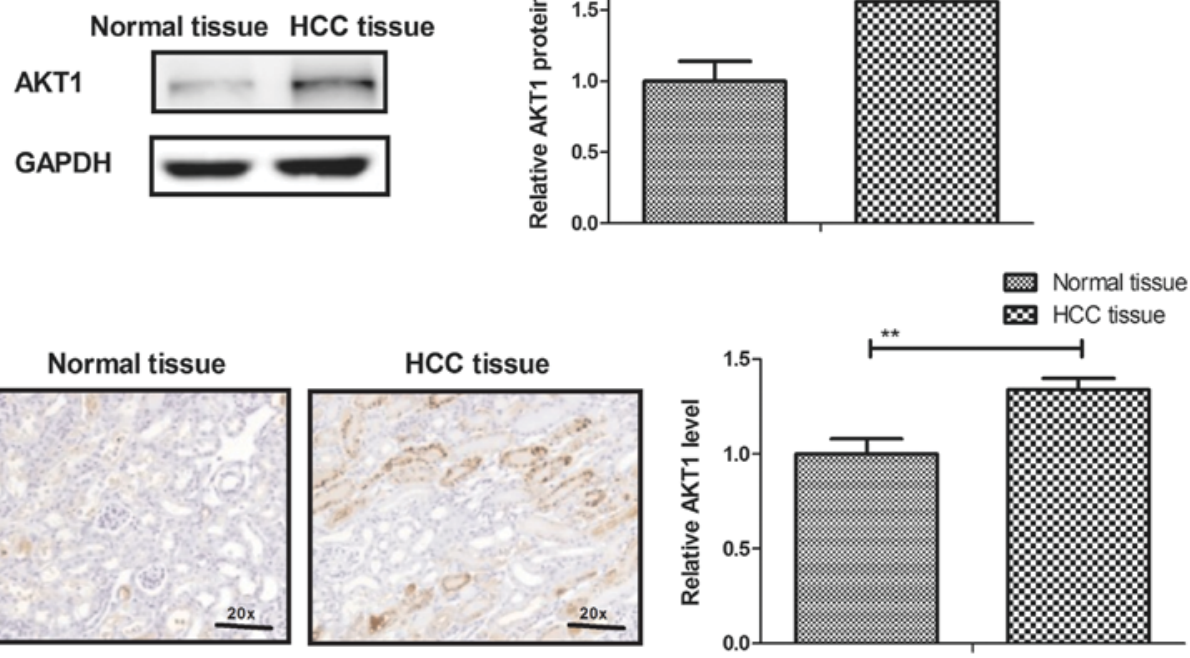

Figure 1. Expression levels of AKT1 between HCC tissues and adjacent normal tissues. AKT1 gene (A) and protein (B) expression levels were significantly higher in HCC tissues than adjacent normal tissues. (C) The AKT1-positive cells in HCC tissues were higher than adjacent normal tissues. Magnification, $\mathrm{x} 20$. ${ }^{* *} \mathrm{P}<0.01$. HCC, hepatocellular carcinoma.

A

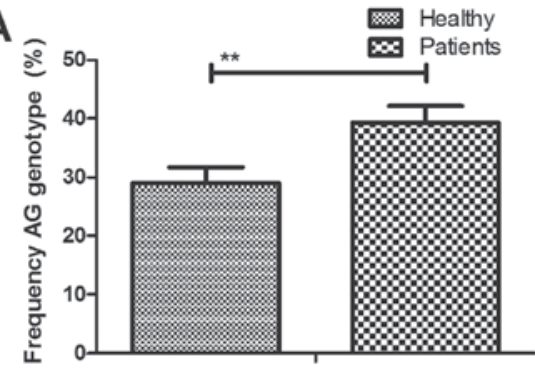

C

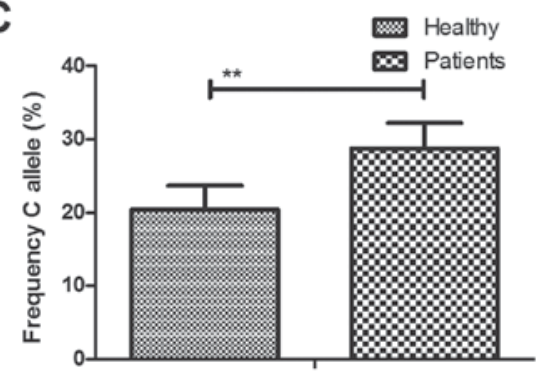

B
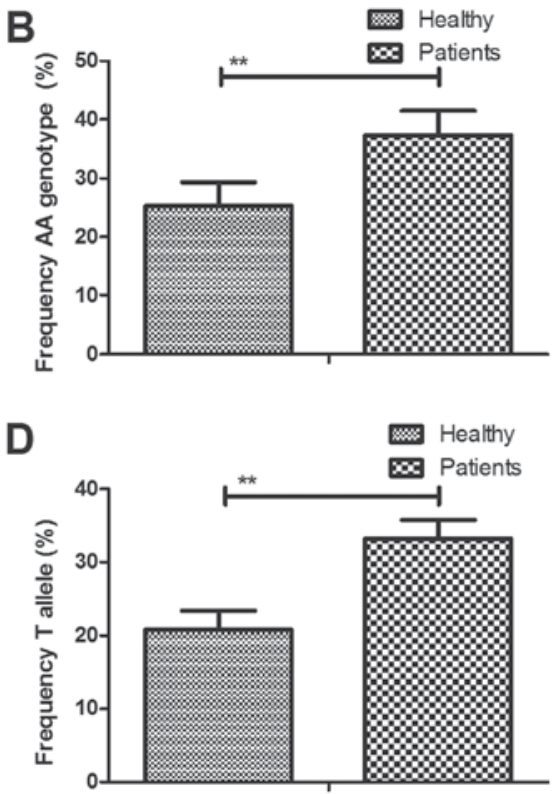

Figure 2. Meta-analysis AKT1 rs2494752 gene polymorphism between hepatocellular carcinoma patients and healthy individuals. HCC patients had a higher frequency of $A K T$ rs2494752 AG (A) and AA (B) genotypes than healthy individuals. HCC patients had a higher frequency of $A K T$ rs $2494752 \mathrm{C}(\mathrm{C})$ and T (D) alleles than healthy individuals. ${ }^{* *} \mathrm{P}<0.01$. HCC, hepatocellular carcinoma.

dimension reduction was conducted in HCC patients. We showed that $A K T$ rs2494752 AA genotype had a vital increased susceptibility to $\mathrm{HCC}$ in the dominant model $(\mathrm{P}=0.028$; Fig. 5A). We observed significant differences between rs2494752 C and T alleles for susceptibility HCC patients ( $\mathrm{P}=0.0384$, Fig. 5B). These results suggest that $A K T 1$ rs2494752 AA genotype is associated with the risk of hepatocellular carcinoma. 
A

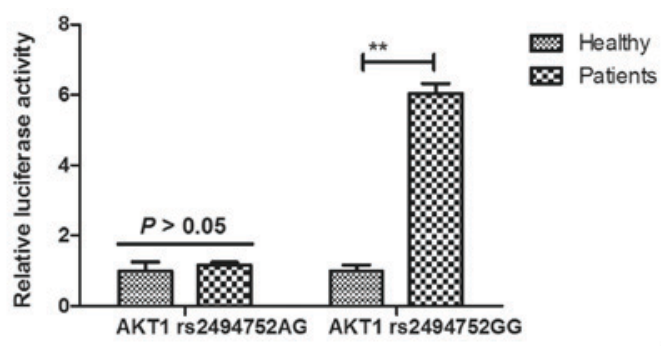

B

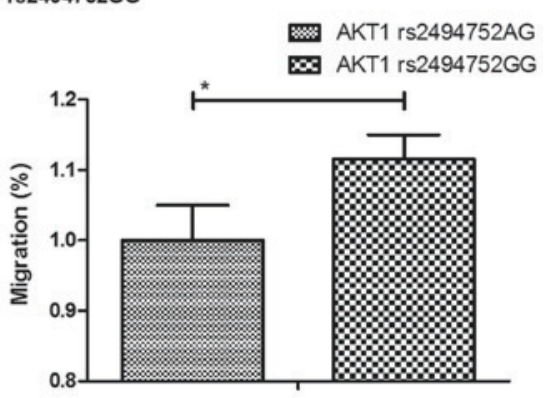

C

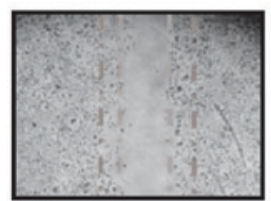

AKT1 rs2494752AG

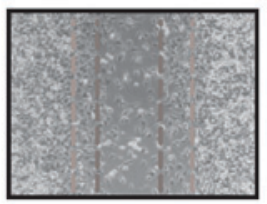

AKT1 rs2494752T

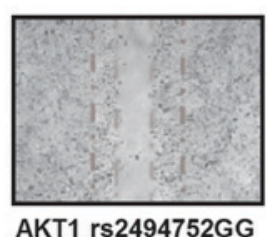

AKT1 rs2494752GG

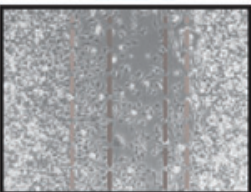

AKT1 rs2494752C

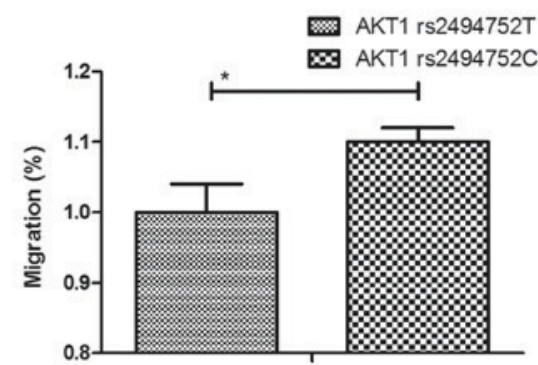

Figure 3. Effects of the $A K T 1$ rs 2494752 on $A K T 1$ transcriptional activity and progression of HCC. (A) HCC patients harboring AKT1 rs2494752 GG genotype promoted $A K T 1$ promoter activity. HCC patients harboring AKT1 rs2494752 GG (B) and C (C) presented more aggressive than other $A K T 1$ rs2494752 cancer cells. ${ }^{*} \mathrm{P}<0.05,{ }^{* *} \mathrm{P}<0.01$. HCC, hepatocellular carcinoma.
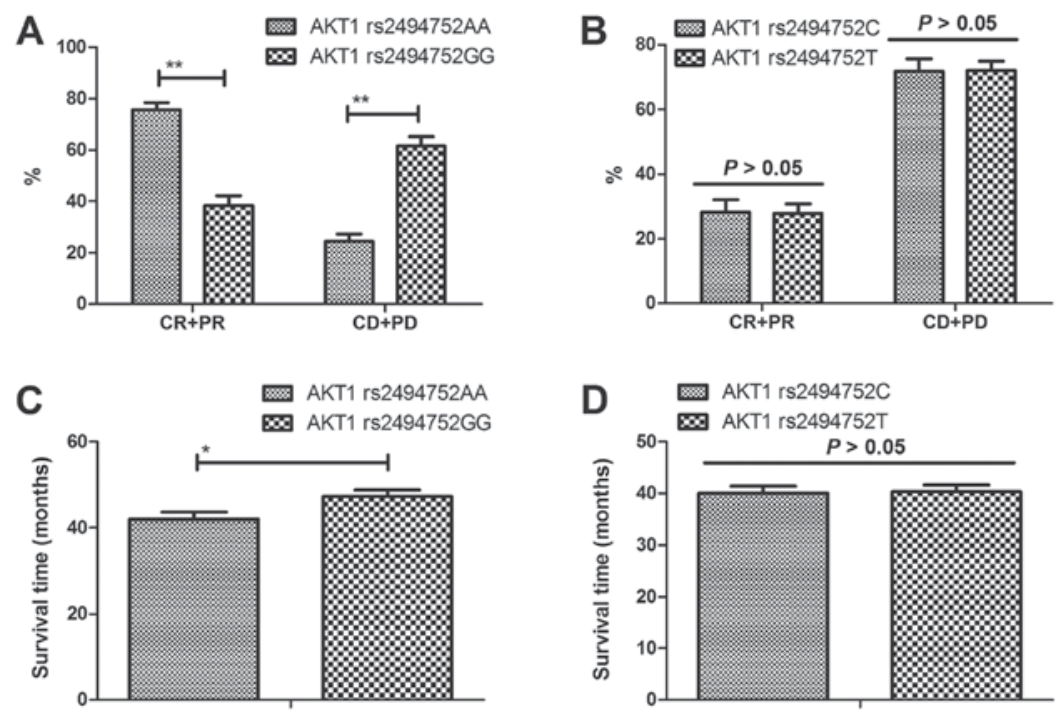

Figure 4. Effects of $A K T 1$ rs2494752 gene polymorphism on response to NCT and the survival of HCC patients. (A) AKT1 rs2494752 GG increased rates of response to NCT chemotherapy compared to the $A K T 1 \mathrm{rs} 2494752$ AA genotype. (B) No significant differences between $A K T 1 \mathrm{rs} 2494752 \mathrm{C}$ and T alleles in responding to NCT chemotherapy. (C) AKT1 rs2494752 GG patients show a long-term survival. (D) No significant differences were observed between $A K T 1$ rs $2494752 \mathrm{C}$ and $\mathrm{T}$ alleles for $\mathrm{HCC}$ patients. $\mathrm{P}<0.05,{ }^{* *} \mathrm{P}<0.01$. HCC, hepatocellular carcinoma; $\mathrm{CR}$, complete response, $\mathrm{PR}$, partial response, $\mathrm{PD}$, progressive disease, $\mathrm{SD}$, stable disease.

\section{Discussion}

$\mathrm{HCC}$ is the most common primary liver malignancy and it is a leading cause of cancer-related death worldwide (24).
Researches have suggested that gene polymorphism is associated with the risk and poor survival in a 5-year survival statistical survey for HCC patients $(10,11,25)$. Importantly, a meta-analysis has indicated that the rs 2494752 polymorphism of 

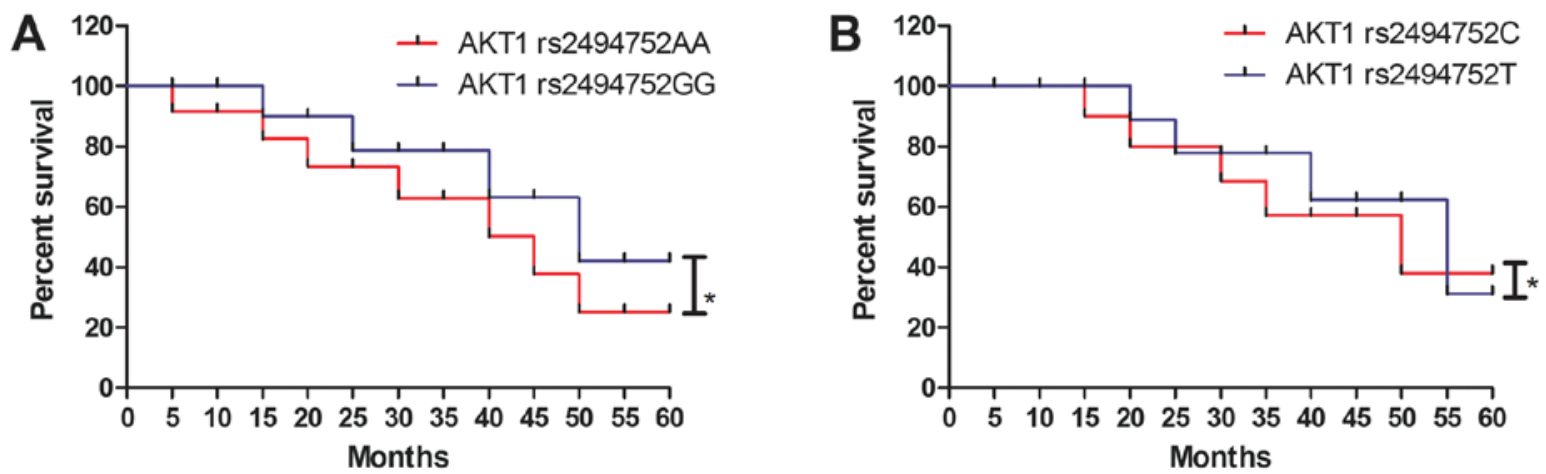

Figure 5. Meta-analysis between AKT1 rs2494752 gene polymorphism and risk of HCC. (A) AKT rs2494752 AA genotype presents a vital increased susceptibility to HCC. (B) Significant differences between rs $2494752 \mathrm{C}$ and T alleles for susceptibility HCC patients. ${ }^{*} \mathrm{P}<0.05$. HCC, hepatocellular carcinoma.

$A K T 1$ can be used to predict susceptibility and $\mathrm{CE}(\mathrm{A}) \mathrm{F}$ chemotherapy response to breast cancer and clinical outcomes (26). In this study, we investigated the association between $A K T 1$ rs2494752 gene polymorphism and risk of hepatocellular carcinoma, as well as metastasis of HCC cells. Here, we showed a higher frequency of $A K T$ rs 2494752 AG/AA genotypes and C/T alleles in HCC cases. Outcomes found that AKT1 rs2494752 GG genotype showed an increasing of $A K T 1$ promoter activity determined by the luciferase assay. Results demonstrated that $A K T 1$ rs2494752 GG genotype is more aggressive than other $A K T 1$ rs 2494752 cancer cells. We also indicated that $A K T 1$ rs 2494752 GG significantly increased rates of response to NCT chemotherapy and AKT1 rs 2494752 GG and C increased the risk factors of hepatocellular carcinoma.

Currently, gene polymorphism is associated with tumor diagnosis, target therapy and prognosis (27-29). Previous study has showed the functional polymorphism (rs2494752) in the AKT1 promoter region and gastric adenocarcinoma risk in an eastern Chinese population, which suggested that the potentially functional AKT1 rs 2494752 single nucleotide polymorphism (SNP) may affect GCa susceptibility by modulating the AKT1 promoter transcriptional activity (30). Wu et al (31), have suggested that Pre-miR-149 rs71428439 polymorphism is associated with the increased cancer risk and AKT1/cyclinD1 signaling in hepatocellular carcinoma. In this study, we observed that $A K T 1$ rs2494752 gene polymorphism AG/AA genotype and $\mathrm{C} / \mathrm{T}$ allele in $A K T 1$ is higher frequencies in HCC patients compared to healthy individuals. Our outcomes revealed that AKT1 rs2494752 polymorphism GG and C promoted AKT1 transcriptional activity and aggressiveness of hepatocellular carcinoma. However, we only chose SNP allele (AG, AA, C, and T) in HCC and healthy hepatic tissue. The effect of AKT rs2494752 SNP in AG, C, T, and GG allele on AKT1 transcriptional activity need further investigated in future work.

Previous study has revealed that HCC is genetically complex, multifactorial and heterogeneous tumor (32). AKT mediates various signal pathways, which may provide a novel strategy to improve the therapeutic efficiency of HCC via regulation of apoptosis sensitivity induced by chemotherapy $(33,34)$. Wang et al (35), have suggested that molecularly targeting the PI3K pathway can sensitize cancer cells to radiotherapy and chemotherapy. We reported that AKT1 rs2494752 AKT1 rs2494752 GG genotype increased response to NCT and the survival of HCC patients. We also indicated that $A K T 1$ rs2494752 AA genotype is associated with the higher risk of HCC than AKT1 rs2494752 GG genotype. However, this study did not report the associations between cancer staging or metastasis status and AKT rs2494752 SNP. Further study should be performing to analyze the AKT rs2494752 SNP with other clinical data such as hepatocellular cancer staging or metastasis status in a large population.

In conclusion, the present study provided evidences that AKT1 rs2494752 polymorphism is associated with susceptibility, metastasis, chemotherapy sensitivity and prognosis in HCC patients. Our results indicate that $A K T 1$ rs2494752 AA genotype is associated with the risk of hepatocellular carcinoma, which may be a vital response to chemotherapy and prognostic indicator for HCC patients. Findings also suggest that AKT1 rs2494752 may be a candidate biomarker for the prediction of susceptibility and prognosis in $\mathrm{HCC}$ patients after chemotherapy.

\section{Acknowledgements}

Not applicable.

\section{Funding}

No funding was received.

\section{Availability of data and materials}

The analyzed data sets generated during the present study are available from the corresponding author on reasonable request.

\section{Authors' contribution}

ZHW and HLF designed the study. WL and HLF performed the experiments. WL and ZHW analyzed the data.

\section{Ethics approval and consent to participate}

This study was approved by the ethics committee of Qingdao Sixth People's Hospital (ethics code: QDPHCAN132X1P). All patients provided informed consent.

\section{Consent for publication}

Not applicable. 


\section{Competing interests}

The authors declare that they have no competing interests.

\section{References}

1. Muto J, Shirabe K, Sugimachi K and Maehara Y: Review of angiogenesis in hepatocellular carcinoma. Hepatol Res 45: 1-9, 2015.

2. Pang Q, Qu K, Bi JB, Liu SS, Zhang JY, Song SD, Lin T, Xu XS, Wan Y, Tai MH, et al: Thrombocytopenia for prediction of hepatocellular carcinoma recurrence: Systematic review and meta-analysis. World J Gastroenterol 21: 7895-7906, 2015.

3. Parikh ND, Waljee AK and Singal AG: Downstaging hepatocellular carcinoma: A systematic review and pooled analysis. Liver Transpl 21: 1142-1152, 2015.

4. Qi X, Liu L, Wang D, Li H, Su C and Guo X: Hepatic resection alone versus in combination with pre- and post-operative transarterial chemoembolization for the treatment of hepatocellular carcinoma: A systematic review and meta-analysis. Oncotarget 6: 36838-36859, 2015.

5. Seshadri RM, Baker EH, Templin M, Swan RZ, Martinie JB, Vrochides D and Iannitti DA: Outcomes of surgical resection and loco-regional therapy in patients with stage $3 \mathrm{~A}$ hepatocellular carcinoma: A retrospective review from the national cancer database. HPB (Oxford) 17: 964-968, 2015.

6. Yang XD, Pan LH, Wang L, Ke Y, Cao J, Yang C, Zhong JH, Luo W, Guo J and Li LQ: Systematic review of single large and/or multinodular hepatocellular carcinoma: Surgical resection improves survival. Asian Pac J Cancer Prev 16: 5541-5547, 2015.

7. Zhu GQ, Shi KQ, Yu HJ, He SY, Braddock M, Zhou MT, Chen YP and Zheng MH: Optimal adjuvant therapy for resected hepatocellular carcinoma: A systematic review with network meta-analysis. Oncotarget 6: 18151-18161, 2015.

8. Simonetti RG, Cammà C, Fiorello F, Politi F, D'Amico G and Pagliaro L: Hepatocellular carcinoma. A worldwide problem and the major risk factors. Dig Dis Sci 36: 962-972, 1991.

9. Zidan A, Scheuerlein H, Schüle S, Settmacher U and Rauchfuss F: Epidemiological pattern of hepatitis $\mathrm{B}$ and hepatitis $\mathrm{C}$ as etiological agents for hepatocellular carcinoma in iran and worldwide. Hepat Mon 12: e6894, 2012.

10. Suo GJ and Zhao ZX: Association of the interleukin-28B gene polymorphism with development of hepatitis virus-related hepatocellular carcinoma and liver cirrhosis: A meta-analysis. Genet Mol Res 12: 3708-3717, 2013.

11. Park MS, Kim SK, Shin HP, Lee SM and Chung JH: TXNDC5 gene polymorphism contributes to increased risk of hepatocellular carcinoma in the Korean male population. Anticancer Res 33: 3983-3987, 2013.

12. Yeh CT, Liang KH, Lin CC, Chang ML, Hsu CL and Hung CF: A single nucleotide polymorphism on the GALNT14 gene as an effective predictor of response to chemotherapy in advanced hepatocellular carcinoma. Int J Cancer 134: 1214-1224, 2014

13. Duan C, Zhang W, Lu J, Wu H, Liu M and Zhu W: DNA repair gene XRCC3 Thr241Met polymorphism and hepatocellular carcinoma risk. Tumour Biol 34: 2827-2834, 2013.

14. Liu T, Gulinaer A, Shi X, Wang F, An H, Cui W and Li Q: Gene polymorphisms in the PI3K/AKT/mTOR signaling pathway contribute to prostate cancer susceptibility in Chinese men. Oncotarget 8: 61305-61317, 2017.

15. Piao Y, Li Y, Xu Q, Liu JW, Xing CZ, Xie XD and Yuan Y: Association of MTOR and AKT gene polymorphisms with susceptibility and survival of gastric cancer. PLoS One 10: e0136447, 2015.

16. He ML, Wu Y, Zhao JM, Wang Z and Chen YB: PIK3CA and AKT gene polymorphisms in susceptibility to osteosarcoma in a Chinese population. Asian Pac J Cancer Prev 14: 5117-5122, 2013.

17. Yin P, Zhao C, Li Z, Mei C, Yao W, Liu Y, Li N, Qi J, Wang L, Shi Y, et al: Spl is involved in regulation of cystathionine $\gamma$-lyase gene expression and biological function by PI3K/Akt pathway in human hepatocellular carcinoma cell lines. Cell Signal 24: 1229-1240, 2012.
18. Xu J, Jia L, Ma H, Li Y, Ma Z and Zhao Y: Axl gene knockdown inhibits the metastasis properties of hepatocellular carcinoma via PI3K/Akt-PAK1 signal pathway. Tumour Biol 35: 3809-3817, 2014.

19. Livak KJ and Schmittgen TD: Analysis of relative gene expression data using real-time quantitative PCR and the 2(-Delta Delta C(T)) method. Methods 25: 402-408, 2001.

20. Almeida Mde A, Pizzini CV, Damasceno LS, Muniz Mde M, Almeida-Paes R, Peralta RH, Peralta JM, Oliveira Rde V, Vizzoni AG, de Andrade CL and Zancopé-Oliveira RM: Validation of western blot for Histoplasma capsulatum antibody detection assay. BMC Infect Dis 16: 87, 2016.

21. Dirani M, Nasreddine W, Abdulla F and Beydoun A: Seizure control and improvement of neurological dysfunction in Lafora disease with perampanel. Epilepsy Behav Case Rep 2: 164-166, 2014.

22. Santin I, Castellanos-Rubio A, Hualde I, Castaño L, Vitoria JC and Bilbao JR: Toll-like receptor 4 (TLR4) gene polymorphisms in celiac disease. Tissue Antigens 70: 495-498, 2007.

23. Suzuki S, Hosomichi K, Yokoyama K, Tsuda K, Hara H, Yoshida Y, Fujiwara A, Mizutani M, Shiina T, Kono T and Hanzawa K: Primary analysis of DNA polymorphisms in the TRIM region (MHC subregion) of the Japanese quail, Coturnix japonica. Anim Sci J 84: 90-96, 2013.

24. Balogh J, Victor D III, Asham EH, Burroughs SG, Boktour M, Saharia A, Li X, Ghobrial RM and Monsour HP Jr: Hepatocellular carcinoma: A review. J Hepatocell Carcinoma 3: 41-53, 2016.

25. Wu X, Xin Z, Zhang W, Zheng S, Wu J, Chen K, Wang H, Zhu X, Li Z, Duan Z, et al: A missense polymorphism in ATF6 gene is associated with susceptibility to hepatocellular carcinoma probably by altering ATF6 level. Int J Cancer 135: 61-68, 2014.

26. Li X, Zhang R, Liu Z, Li S and Xu H: The genetic variants in the PTEN/PI3K/AKT pathway predict susceptibility and CE(A)F chemotherapy response to breast cancer and clinical outcomes. Oncotarget 8: 20252-20265, 2017.

27. Dai X, Zhang X, Wang B, Wang C, Jiang J and Wu C: Association between polymorphism rs678653 in human cyclin D1 gene (CCND1) and susceptibility to cancer: A meta-analysis. Med Sci Monit 22: 863-874, 2016

28. Kowal A, Wiśniewski A, Kuśnierczyk P and Jankowska R: Human leukocyte antigen (HLA)-G gene polymorphism in patients with non-small cell lung cancer. Thorac Cancer 6: 613-619, 2015.

29. Azimzadeh P, Romani S, Mirtalebi H, Fatemi SR, Kazemian S, Khanyaghma $\mathrm{M}$ and Mohebbi SR: Association of co-stimulatory human B-lymphocyte antigen B7-2 (CD86) gene polymorphism with colorectal cancer risk. Gastroenterol Hepatol Bed Bench 6: 86-91, 2013.

30. Wang MY, He J, Zhu ML, Teng XY, Li QX, Sun MH, Wang XF, Yang YJ, Wang JC, Jin L, et al: A functional polymorphism (rs2494752) in the AKT1 promoter region and gastric adenocarcinoma risk in an eastern chinese population. Sci Rep 6: 20008, 2016.

31. Wu J, Lv S, An J and Lu C: Pre-miR-149 rs71428439 polymorphism is associated with increased cancer risk and AKT1/cyclinD1 signaling in hepatocellular carcinoma. Int J Clin Exp Med 8: 13628-13633, 2015.

32. Salati U, Barry A, Chou FY, Ma R and Liu DM: State of the ablation nation: A review of ablative therapies for cure in the treatment of hepatocellular carcinoma. Future Oncol 13: 1437-1448, 2017.

33. Wu L, Zheng J, Chen P, Liu Q and Yuan Y: Small nucleolar RNA ACA11 promotes proliferation, migration and invasion in hepatocellular carcinoma by targeting the PI3K/AKT signaling pathway. Biomed Pharmacother 90: 705-712, 2017.

34. Gong L, Di C, Xia X, Wang J, Chen G, Shi J, Chen P, Xu H and Zhang W: AKT/mTOR signaling pathway is involved in salvianolic acid B-induced autophagy and apoptosis in hepatocellular carcinoma cells. Int J Oncol 49: 2538-2548, 2016.

35. Wang Z, Huang Y and Zhang J: Molecularly targeting the PI3K-Akt-mTOR pathway can sensitize cancer cells to radiotherapy and chemotherapy. Cell Mol Biol Lett 19: 233-242, 2014.

This work is licensed under a Creative Commons Attribution-NonCommercial-NoDerivatives 4.0 International (CC BY-NC-ND 4.0) License. 